\title{
Educação Ambiental na visão ecoturística: turismo e desenvolvimento local no município de Rio das Ostras (RJ)
}

\author{
Environmental Education in the ecotouristic vision: tourism and local \\ development in municipality of Rio das Ostras (RJ, Brazil)
}

\section{Bruna Cirino Carvalho, Vivian Castilho da Costa}

\begin{abstract}
RESUMO
O Turismo se releva como uma atividade de um intenso consumo da paisagem, transformador e modificador dos espaços, principalmente das áreas naturais que hoje se tornaram o foco para a prática turística. Neste contexto, a inserção da educação ambiental nas atividades ecoturísticas, preocupa-se em integrar os diferentes sujeitos envolvidos nestas atividades. Essa pesquisa tem como objetivo analisar as relações entre o ecoturismo e a educação ambiental, além de identificar suas possibilidades e potencialidades na conservação da natureza, tendo como área de estudo o município de Rio das Ostras (RJ). Assim analisam-se as atividades de ecoturismo na cidade com respeito a Educação Ambiental (EA), e se esta conduz à praticas eficazes com ações e estratégias, que além de desenvolver uma percepção em todos os sujeitos envolvidos, precisa ressaltar e orientar propostas de conscientização tendo como principal objetivo divulgar aos visitantes atividades que orientem formas de uso e preservação da natureza. No caso do município de Rio das Ostras, a área analisada foi o Parque dos Pássaros, que é uma Unidade de Conservação de proteção Integral, e se organiza de forma a orientar programas de ecoturismo, além de abrigar o Núcleo de EA da cidade. A ideia destas atividades é fazer com que a comunidade local perceba a importância da preservação do meio ambiente, para que posteriormente consiga passar aos visitantes e turistas os princípios básicos da EA, além de ser uma forma de conservação do produto turístico do município. No presente trabalho percebeu-se que as ações ainda estão restritas aos seus moradores e ainda não há uma disseminação do conhecimento de EA aplicado ao ecoturismo, sem destacar assim a Educação Ambiental como ferramenta de envolvimento socioambiental e construção de atividades para a preservação do meio ambiente, onde a inclusão das comunidades locais assuma importante papel para o desenvolvimento sustentável.
\end{abstract}

PALAVRAS-CHAVE: Educação Ambiental; Ecoturismo; Conscientização Ambiental; Desenvolvimento Local. 


\section{ABSTRACT}

Tourism is an activity falls like a heavy demand on landscape, transforming and modifying spaces, especially of natural areas which today has become the focus for tourist practice. In this context, the inclusion of environmental education in ecotourism activities, is concerned with integrating the different subjects involved in these activities. This research aims to analyze the relationship between ecotourism and environmental education, and to identify possibilities and potentialities in nature conservation, with the study area of the municipality of Rio das Ostras (RJ, Brazil). So we analyze the ecotourism activities in the city under the guidance of Environmental Education (EE), which leads the practices effectively with actions and strategies that besides developing a perception in all subjects involved, need to emphasize and guide proposals awareness with the primary objective to disclose activities that guide visitors ways to use and conserve nature. In the case of Rio das Ostras, the analyzed area was the Park of the Birds, which is a conservation protection Integral, and is organized for development activies of ecotourism, besides housing the EE Center of the town. The idea of these activities is to make the local community realize the importance of preserving the environment, that can later pass on to visitors and tourists the basic principles of $E E$ as well as being a form of conservation in tourism for the municipality. In this study it was found that the actions are still restricted to residents and there is still no knowledge dissemination of EE applied to ecotourism, not just highlight environmental education as a tool for engagement and environmental construction activities for the preservation of the environment where the inclusion of local communities plays an important role for sustainable development.

KEYWORDS: Environmental Education; Ecotourism; Environmental Awareness; Local Development.

\section{Introdução}

O turismo é um fenômeno em expansão no mundo, movimentando cada vez mais pessoas e em crescente volume de capital. Para a OMT (2003, p. 5) "o turismo compreende atividades realizadas por pessoas durante as viagens e estadias em lugares distintos de seu entorno habitual por um período de tempo e consecutivo inferior a um ano, por motivo de férias, negócios e outros".

O turismo assim como outras atividades pode ser considerado um fenômeno social. Sendo este de grande interação com as diferentes camadas sociais, de forma que interfere, por exemplo, na economia e infraestrutura. A atividade turística pode ser ainda, um grande poluidor, responsável por exclusão social, concentração de renda, modificador dos espaços e que se apropria das paisagens para suas práticas. Podemos destacar alguns outros reflexos, pouco percebidos, gerados pela intensificação desta atividade, principalmente quando realizado de forma não e/ou mal planejada. Efeitos como a valorização do solo urbano, a valorização estética de paisagem, mercado de trabalho sazonal, alto custo de vida, crescimento demográfico acelerado (escala espaço-temporal) e espaços de consumo diferenciados, às vezes segregados 
são constantes aliados de impactos ambientais negativos na natureza e na sociedade que podem ser promovidos sem um turismo sustentável.

A cultura de consumo, na qual nossa sociedade esta inserida tem a produção de mercadorias como premissa, onde tudo pode ser transformado em produto desde que tenha mercado interessado.

Com o aumento da importância da venda do produto turístico "meio ambiente" e do mercado consumidor, o turismo tradicional se torna mais popular, não há preocupação com o uso consciente ou a preservação, somente valorizasse o uso presente, sem se importar com as consequências futuras do uso não planejado.

Assim a natureza tem, recentemente, conseguido cada vez mais espaço nas discussões nas diferentes esferas do cenário mundial e, cada vez mais, a Educação Ambiental tem sido uma importante ferramenta na implementação de ações complementares para o uso consciente das áreas naturais. A inserção da educação ambiental nas atividades ecoturísticas, preocupa-se em integrar os diferentes sujeitos envolvidos nestas atividades. As mudanças de comportamento em relação ao meio ambiente somente ocorrerão quando a sociedade em geral tiver assimilado, conscientemente, a ideia de harmonizar as preocupações e valores dos indivíduos com os problemas concretos da proteção à natureza, num contexto integrado e associativo entre sujeito e objeto (homem-natureza) (COSTA; COSTA, 2005).

Nesse contexto, a educação ambiental se configura como uma ferramenta que contribui para a mudança de mentalidades e de atitudes na relação homem - ambiente. Para realizar um trabalho de educação ambiental se faz necessário um levantamento das diversas percepções do ambiente para obter a visão que o outro tem do seu lugar e do seu espaço (BEZERRA; FELICIANO; ALVES, 2008).

Reigota (2007) defende que para que possamos realizar a educação ambiental é necessário obter o conhecimento das visões do meio ambiente pelas pessoas envolvidas na atividade, ou seja, identificar as percepções dos atores sociais envolvidos no contexto do meio ambiente.

Pretende-se objetivamente com este trabalho avaliar a importância da Educação Ambiental (EA) em área protegida e identificar a relação da EA nas atividades ecoturísticas a partir do contexto da Educação Ambiental informal, que se caracteriza por práticas educativas realizadas fora do ambiente escolar com flexibilidade de métodos e conteúdos que buscam a sensibilização da coletividade sobre as diferentes questões ambientais, utilizando como exemplo as práticas do município de Rio das Ostras (RJ).

No caso da atividade turística, que produz e se apropria dos espaços além de valorar determinadas paisagens, a conscientização ambiental torna-se necessária para que os diferentes sujeitos sociais envolvidos nestas práticas percebam suas ações diretas e indiretas no meio em perspectivas futuras. "O espaço do/ou para o turismo constitui uma mercadoria complexa, pois ele mesmo é uma mercadoria. Trata-se da natureza, ou da produção social, incorporada em outra mercadoria, mas como parte do mesmo consumo/produção do espaço" (RODRIGUES, 1999, p. 56). 


\section{Relações entre a geografia do turismo e o meio ambiente}

A atividade turística se utiliza do espaço para seu desenvolvimento, de forma a consumi-los, valorizando-os e assim definindo-os como produtivos, podendo ainda adaptar para o que serão destinados. De forma que isso cria dentro de um espaço "turistificado" dicotomias, onde localidades passam a ser muito valorizadas e outras pouco. Segundo Cruz (2007), se partirmos da premissa de que o principal objeto de consumo do turismo é o espaço e que esta atividade acaba por transformá-lo em mercadoria, uma forma efetiva de criar, tornar público e fazer com que o lugar turístico seja reconhecido é o marketing. Este se utiliza dos aspectos característicos que podem ser atrativos e os levam ao conhecimento, a forma mais utilizada de propagação destas informações que é a mídia. Neste caso a mídia se torna um importante influenciador na construção imaginária de um bom lugar para a prática do turismo.

Segundo Becker (1996), o marketing e as redes de informação e de circulação são capazes de atrair um crescente número de consumidores, e inseri-los num circuito de consumo através de pacotes e similares, que caracterizam o comportamento da sociedade contemporânea que prima pelo consumo.

Com o marketing turístico inicia-se de forma maciça a exploração do espaço, concomitante a venda da natureza, a partir do turismo natural. Neste contexto podemos destacar a existência de uma infinidade de modalidades do turismo, por exemplo, os conceitos de turismo de aventura, de sol e mar, entre outros, onde o trabalho de readequação espacial será feito de forma intensa. Além da criação de pontos focais, o marketing se ocupa em destacar pontos que serão, em dado momento, as principais atrações, criando no consumidor o desejo do consumo pela lógica da oferta. Milton Santos (2001, p.48) compartilha do mesmo entendimento a cerca das mudanças do sentido do consumo ao longo do tempo, enfatizando que se antes as indústrias preocupavam-se com autonomia de produção, "atualmente, as empresas hegemônicas produzem o consumidor antes mesmo de produzir os produtos".

O turismo pode ser visto como uma atividade dicotômica no mundo contemporâneo, porque se por um lado é gerador de grandes transformações econômicas e riquezas por outro pode ser um grande contribuinte para uma crise ambiental, quando identificamos a intensificação da relação homem - natureza.

Esta relação pode surgir e se intensificar quando o homem sente a necessidade de usufruir do espaço natural para atender as suas necessidades. Podemos observar que o turismo está inserido nesta relação, onde os recursos ambientais para o turismo supõem o significado de conotação econômica. A atividade em si perpassa qualquer ética de relacionamento integrado e de preservação quando se trata de atender as necessidades humanas. Ruschmann (1997) considera o turismo como um intenso consumidor da natureza, o mesmo ainda afirma que nos últimos decênios, sua evolução ocorreu como resultado da "busca do verde" e da "fuga" dos tumultos da urbanização pelas pessoas que tentam recuperar o equilíbrio psicológico e físico em contato com a natureza em seu tempo de lazer. 
A Natureza é o continente e o conteúdo do homem, incluindo os objetos, as ações, as crenças, os desejos, a realidade esmagadora e as perspectivas. Com a presença do homem sobre a Terra a natureza está sendo sempre redescoberta, desde o fim de sua história Natural e a criação da Natureza Social, ao desencantamento do Mundo, com a passagem de uma ordem vital a uma ordem racional (SANTOS, 1992, p. 4).

O primeiro aspecto destacável nesta relação seria a atribuição de valor, comercial em sua maioria, à natureza pelo homem. No ambiente turístico o meio natural tem importante destaque, principalmente quando é um lugar ainda nativo, que representa no imaginário do turista, um lugar exótico, diferente, que pode ser explorado pelo homem.

Para Cruz (2003), não há atividade humana que não interfira nos ambientes, de alguma forma, é impossível o homem viver sobre este planeta sem transformá-lo. E diz também que em alguns casos há algum erro estratégico de planejamento subjacente ao processo de apropriação dos lugares pela atividade ou simplesmente, o planejamento jamais existiu.

O turismo praticado neste meio não somente gera impactos diretos, como a relação intensificada do homem com o meio, mas também de forma indireta, porque em função deste há a necessidade da criação de um aparato mínimo para dar suporte às práticas. Assim, instalam-se novos empreendimentos (moradias, alimentação etc.), a criação de infraestrutura sanitária (para o destino e tratamento de esgoto e resíduos produzidos), a coleta de lixo, entre outras necessidades básicas para a manutenção do ambiente desejável para a prática turística. As localidades receptoras sofrem diferentes impactos assim como descreve Ruschmann (1997):

Os impactos do turismo referem-se à gama de modificações ou à sequencia de eventos provocados pelo processo de desenvolvimento turístico nas localidades receptoras. As variáveis que provocam os impactos têm natureza, intensidade, direções e magnitude diversas; porém, os resultados interagem e são geralmente irreversíveis quando ocorrem no meio ambiente natural (RUSCHMANN, 1997, p.34).

O turismo atribui valor aos espaços, transformando-os em mercadorias, estabelecendo à sua maneira, formas de uso. Estes "novos espaços" são criados eminentemente turísticos com pouca ou muitas vezes nenhuma interação com as comunidades nativas, que acabam marginalizadas com relação ao uso dos recursos. A Natureza, espaço público e de uso comum, é transformada em espaço privado, os lugares e até mesmo a população, a cultura local e tudo mais que for de interesse econômico são comercializados e expostos como atrativos turísticos, que podem e devem ser consumidos. Esta intensificação na exploração, em sua maioria, compromete a qualidade de vida local a curto, médio e longo prazo. 


\section{A educação para o turismo: teoria e prática}

Neste aspecto podemos destacar o turismo de natureza, onde a mesma sai do patamar de recurso, e assume o papel de capital, ou seja, como esta pode se tornar fonte de (re) produção do capital. Com este novo significado o mercado turístico se apropria do espaço e da natureza, onde o marketing consegue lançar no mercado mundial o chamado ecoturismo, que segundo a sua política de uso, consegue usar, conservar e preservar o meio natural. Na verdade nesta lógica este tipo de turismo serviria como conscientização do turismo de massa, chamado a atenção para a importância da preservação pensando nos benefícios a curto, médio e longo prazo.

A Organização Mundial do Turismo (2003) assim define o ecoturismo:

O ecoturismo é uma forma de turismo baseada na natureza, com grande ênfase na conservação do meio ambiente, incluindo a diversidade biológica, os sistemas de vida selvagem e ecológicos, ressaltando a importância da educação do turista quanto ao meio ambiente e ao modo de conservá-lo. E ainda considera que o ecoturismo abrange também as comunidades, especialmente de povos tradicionais, que estejam diretamente envolvidas na atividade (OMT, 2003).

O turismo tem uma capacidade incontestável de modificar os espaços, em relação aos ambientes naturais, podemos ressaltar algumas práticas que atingem diretamente estes espaços, principalmente quando se trata de uma nova tendência de turismo - o turismo ambiental ou "ecoturismo". Esta nova tendência "busca", a utilização harmônica do meio natural pelo homem. Assim a Empresa Brasileira do Turismo (EMBRATUR) define o ecoturismo:

Ecoturismo é uma tendência em termos de turismo mundial que aponta para o uso sustentável de atrativos no meio ambiente e nas manifestações culturais, devemos ter em conta que somente teremos condições de sustentabilidade caso haja harmonia e equilíbrio no 'dialogo' entre os seguintes fatores: resultado econômico, mínimos impactos ambientais e culturais, satisfação do ecoturista (visitante, cliente, usuários) e da comunidade (visitada) (EMBRATUR, 1995).

O ecoturismo é caracterizado por ser um termo polissêmico, sendo assim, recebe inúmeros tratamentos teóricos para traduzir suas propostas. Como contribuição, Costa (2008) afirma que o ecoturismo, a partir da década de 70, passa a ser rotulado por diversas designações, que aparentemente possuem o mesmo significado, sendo estes: turismo de natureza, turismo ambiental, turismo ecológico, turismo de aventura, turismo verde, dentre outras. Concluindo que independente destas, o importante é que as práticas ecoturísticas tenham como base o tripé composto pela paisagem, a educação para a conservação da natureza e a inclusão social. 
No Brasil as discussões sobre ecoturismo foram iniciadas na década de 80 com a criação do Projeto de Turismo Ecológico, com objetivo de ordenar e compreender o segmento e atividades desta nova ramificação turística. Fato que marca o contexto histórico do Ecoturismo no Brasil foi a elaboração da Política Nacional de Ecoturismo, que foi realizada com a organização do Ministério da Indústria do Comércio e do Turismo e do Ministério do Meio Ambiente, em Goiás (1994), sendo composto por membros desses ministérios e também do IBAMA e EMBRATUR. Pires (1998, p. 75), explicita que o ecoturismo surge e adquire uma "rotulação" que é utilizada de forma amplificada, para expressar um conjunto variado e não bem definido de atividades e atitudes no ramo de viagens que se posicionam na interface turismo e ambiente, sendo o segundo compreendido de forma geral (ambientes naturais), ou seja, pouco alterados.

O ecoturismo surge não para ser tratado como uma nova tendência industrial a ser praticada na natureza, mas uma ferramenta a mais para contribuir com o envolvimento do turista a compreender a dinâmica da localidade a ser visitada. Com isso, despertar um olhar mais interessado sobre os biomas, ecossistemas, relevo, dinâmica geomorfológica entre outros aspectos, fazendo com que estes visitantes consigam despertar em sua subjetividade a importância da preservação para objetivar a conservação tanto do espaço visitado quanto do seu entorno.

Em se tratando de ecoturismo, Ruschmann considera como sendo estruturais para o desenvolvimento sustentável dos recursos ou localidades turísticas, as seguintes medidas, "[...] determinar restrições de acesso e desenvolvimento; impor cotas ou custos extras que limitem a instalação de equipamentos receptivos; delegar poder de decisão às autoridades competentes, responsabilizando-as [...] pelas decisões que envolvem o desenvolvimento" (1994, p. 35).

Sendo assim se faz necessário, como em qualquer outra atividade turística, visar o planejamento, onde seria possível separar o ecoturismo do turismo de massa. Desta forma, esta prática deve vir acompanhada de um conhecimento prévio dos atributos naturais, a exemplo da fauna e flora locais. Identificando ainda as potencialidades e limitações na localidade, e, para tais identificações "todas as atividades devem fazer parte do processo de planejamento e manejo das atividades ecoturísticas" (COSTA, 2008, p. 60).

São nítidas algumas características que deveriam ser consideradas no planejamento destas atividades com visão de conservação, sendo destacável: o envolvimento da comunidade local, a conservação ambiental e a educação. $O$ que não poderíamos deixar de considerar nestas premissas que a lógica de mercado, que busca suprir as demandas do modismo ambiental, vem utilizando-se da prática ecoturística de forma errônea. De forma cotidiana, o que acontece nas atividades turísticas é que o turista é levado a conhecer a área de forma superficial, sem que lhe seja explicado os processos formativos e nem mesmo a forma de preservação do ambiente. Muitas vezes isso ocorre pelo despreparo dos guias, o não envolvimento das comunidades locais ou até mesmo a falta do planejamento e monitoração para a identificação das limitações e possibilidades na localidade. 
[...] é essencial no desenvolvimento de ecoturismo em qualquer região: a implementação do manejo e o monitoramento das ações e dos impactos devem ter a participação das comunidades locais, que muitas vezes se sentem alijadas do processo, inclusive, do próprio uso de atrativos ecoturísticos, em função do valor de acesso ao local (COSTA, 2008, p. 28).

Esta questão torna-se importante, pois como expõe Pires (1998) uma experiência verdadeiramente ecoturística além de precisar do meio natural como cenário, dos atrativos naturais e culturais, depende ainda do comprometimento com o manejo, a conservação e a sustentabilidade dos espaços através da participação efetiva das comunidades locais, por meio da difusão de uma consciência ecológica proporcionada pela Educação Ambiental.

O Brasil, dispõe de uma política nacional específica de educação ambiental (PNEA), elaborada em 1999 pelo ProNEA - Programa Nacional de Educação Ambiental, que tem como principal intenção de "[...] promover a articulação das ações educativas voltadas às atividades de proteção, recuperação e melhoria socioambiental, e de potencializar a função da educação para as mudanças culturais e sociais [...] (Brasil, 2003)". Essa política entende a educação ambiental como:

[...] os processos por meio dos quais o indivíduo e a coletividade constroem valores sociais, conhecimentos, habilidades, atitudes e competências voltadas para a conservação do meio ambiente, bem de uso comum do povo, essencial à sadia qualidade de vida e sua sustentabilidade (BRASIL, 1999, s.n.).

Assim, compreende-se que o ecoturismo seria uma atividade turística interpretativa, de mínimo impacto, em que se busca a conservação, o entendimento e a apreciação do meio ambiente e das culturas visitadas, incentivando a educação e a consciência ambiental, social e cultural por meio de visita e vivência da área como explícita Wearing e Neil (2001).

De forma que, a Educação Ambiental imbuída no Ecoturismo, deve orientar de maneira eficaz ações e estratégias, que além de desenvolver uma percepção em todos os sujeitos envolvidos, deve ainda ressaltar e orientar propostas de conscientização tendo como principal objetivo divulgar aos visitantes atividades inerentes a localidade, além de orientar de que forma ele pode não só usar como também preservar a natureza, participar dela (vivenciar ou experiência), com poder crítico e imbuído de ações positivas, além de entender melhor qual seria a importância disso.

Porém, pode-se ressaltar que o ecoturismo é desenvolvido em áreas, inicialmente, naturais, que compreendem espaços diferenciados ao de educação escolar (formal), sendo assim a importância do desenvolvimento de uma educação ambiental não formal, que prima pelos estudos das relações socioambientais levando em consideração a diversidade e as relações interpessoais, em busca de uma construção coletiva. Sendo de extrema importância o desenvolvimento de uma EA como forma de po- 
tencializar a conservação, incorporando a estas práticas ações de planejamento para elucidar atitudes comportamentais coletivas e comprometidas com o meio ambiente. A educação ambiental não formal é definida na Lei 9795/99 como "as ações e práticas educativas voltadas à sensibilização da coletividade sobre as questões ambientais e à sua organização e participação na defesa da qualidade do meio ambiente" (BRASIL, 1999, s.n.).

Entre estes princípios da Lei 9795/99 no que tange a EA não formal, valem citar - O Poder Público, em níveis federal, estadual e municipal, incentivará: (1) a difusão, por intermédio dos meios de comunicação de massa, em espaços nobres, de programas e campanhas educativas, e de informações acerca de temas relacionados ao meio ambiente; (3) a participação de empresas públicas e privadas no desenvolvimento de programas de educação ambiental em parceria com a escola, a universidade e as organizações não-govemamentais; (4) a sensibilização da sociedade para a importância das unidades de conservação; (5) a sensibilização ambiental das populações tradicionais ligadas as unidades de conservação; (7) o ecoturismo.

Assim a EA no âmbito do ecoturismo deveria ultrapassar a ideia de resultados imediatistas e individualistas, passando a ser um processo continuo de conscientização dos visitantes e também da comunidade local, tendo como objetivo diário a preservação ambiental através de ações concretas que visem sempre transformações benéficas para a sociedade, mesmo que locais.

As práticas de EA não formal devem incentivar momentos de contato do visitante com os ambientes naturais, com o objetivo de sensibilizá-los a compreensão das relações ali existentes, de forma que a percepção deve ser incentivada a partir do lúdico que deve ser utilizado para possibilitar uma consciência conservacionista através, sempre, do envolvimento afetivo e real das pessoas com a natureza e as culturas locais, numa tentativa de apropriação desse território natural, como seu. (NEIMAN; RABINOVICI, 2008).

A educação deve promover o conhecimento para a melhor compreensão e posterior manejo do meio ambiente em favor da humanidade, esta seria uma fonte de criação de informações, conhecimento, conscientização e posterior ação em favor do meio ambiente por parte de todos os envolvidos. Contribuindo para a valorização, proteção e uso sustentável da biodiversidade e meio ambiente, articulando estes a qualidade de vida dos seres humanos (SORRENTINO, TRAJBER, RAYMUNDO, 2007).

Assim não ficando somente no campo das ideias ou na construção teórica, podendo então, a partir destes, criar ações coletivas que construam coletivamente o conhecimento e o compromisso com a real conscientização, como descreve Loureiro (2009):

A Educação Ambiental não atua somente no plano das ideias e no da transmissão de informações, mas no da existência, em que o processo de conscientização se caracteriza pela ação com conhecimentos, pela capacidade de fazermos opções, por se ter compromisso com o outro e com a vida (LOUREIRO, 2009, p. 28). 
Corroborando ao exposto, Mendonça (2000, p.138) destaca que não há possibilidades de construção de uma "[...] consciência conservacionista da natureza se a relação afetiva com ela não estiver impregnada na cultura de um povo [...]'. Desta forma, se o ecoturismo tem como base ser um caminho para a conservação da natureza e também das culturas locais, este precisa facilitar a interação e o diálogo entre os sujeitos envolvidos nestas práticas, para que estes possam contribuir dentro de suas experiências e subjetividades para uma ação efetivamente ecoturística.

\section{Aplicações no município de Rio das Ostras (RJ): Educação Ambiental com participação local}

Rio das Ostras é um município localizado no Estado do Rio de Janeiro e pertence a Região das Baixadas Litorâneas ou Região dos Lagos, conforme TCE-RJ (2008) (Figura 1).

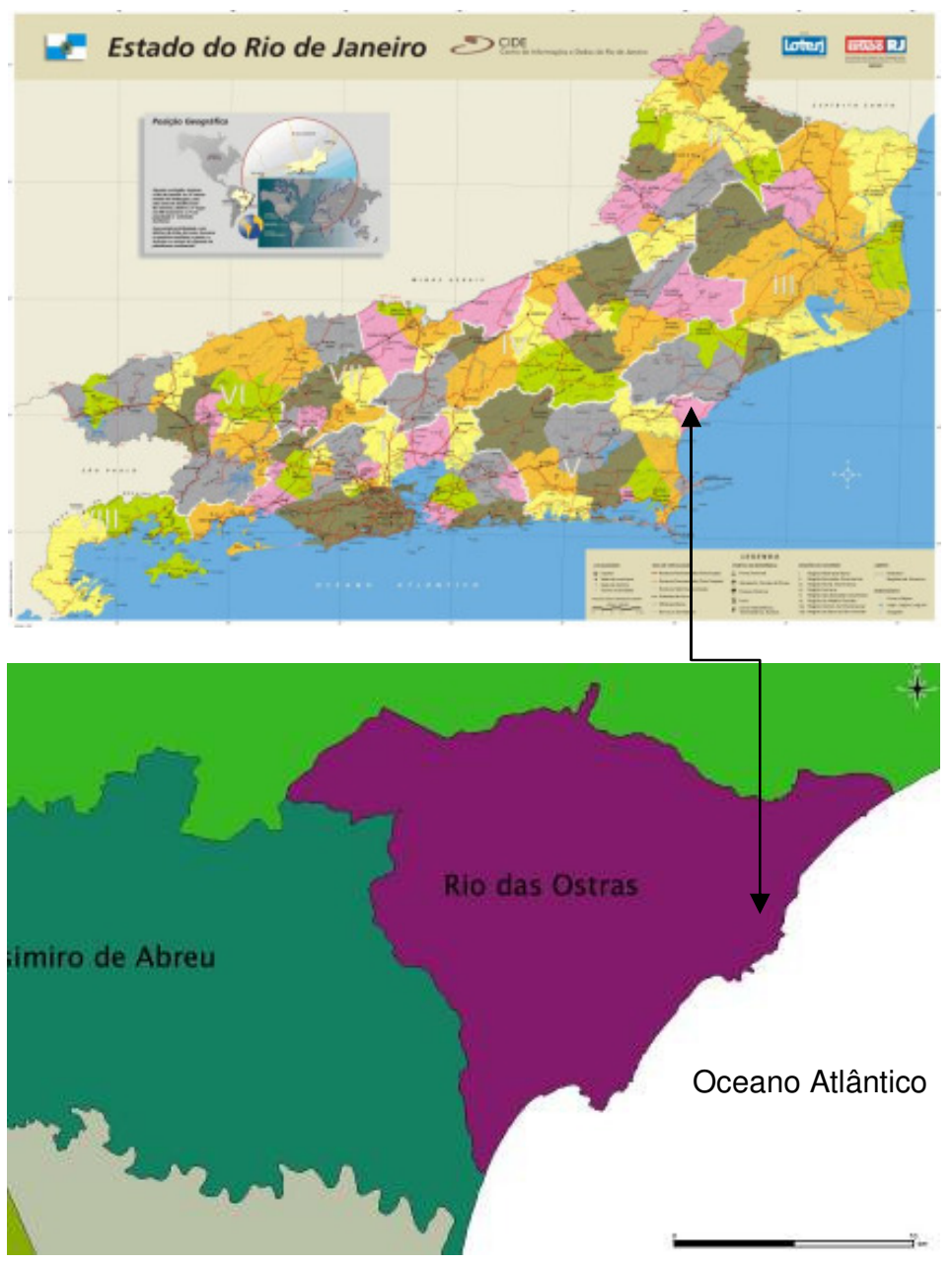

Figura 1: Localização do Município de Rio das Ostras (CIDE, 2008), disponível em www.cide.com.br. Divisão municipal pelo IBGE (2005) realizada no Quantum GIS por Vivian Costa, 2011.

Figure 1: Location of the Municipality of Rio das Ostras (CIDE, 2008), available at www.cide.com.br. Municipal division by IBGE (2005) performed in Quantum GIS by Vivian Costa, 2011. 
O município tem um único distrito-sede, ocupando uma área total de $230,4 \mathrm{~km}^{2}$, correspondentes a 4,2\% da área das Baixadas Litorâneas, está delimitado, no sentido horário, por Macaé, Oceano Atlântico e Casimiro de Abreu. O município tem passado por profundas transformações devido à intensificação da atividade turística. Em sua urbanização, intensamente financiada pelos royalties do petróleo recebidos da Petrobras e pelos impactos ambientais pela utilização do municipio como grande pólo turistico do Estado.

Devido a esta intervenção do petróleo na economia local, o município recebeu para o seu desenvolvimento um projeto que busca trabalhar com o licenciamento ambiental em áreas com atividades de produção, tratamento e escoamento da produção petrolifera. Em definição ampla, o Projeto Pólen é um projeto de Educação Ambiental (Pólos Educativos do Norte-Fluminense e Região) que tem por objetivo principal promover condições para que os diferentes representantes da sociedade (organizações e poder público) além de grupos diretamente ligados a esta atividade, a desenvolva plenamente. Sendo, a partir deste envolvimento através de discussões e encaminhamento da gestão e avaliação de impactos, capazes de compreender a diversidade e complexidade das questões ambientais, desenvolvendo ações que possam contribuir para a diminuição dos impactos socioambientais. Para contribuir, o autor Quintas (2004) descreve que a leitura da problemática ambiental se realiza sob a ótica da complexidade do meio social e o processo educativo sendo pautados por uma postura dialógica, problematizadora e comprometida com as transformações estruturais da sociedade, de cunho emancipatório.

O projeto foi elaborado e também executado pelo NUPEM/UFRJ e fiscalizado pelo IBAMA, que também é responsável pelo licenciamento ambiental. Assim o documento "Conhecimento de aspectos socioambientais e de iniciativas de educação ambiental existentes em municípios da bacia de Campos - RJ - Projeto Polén" (2009), objetiva:

[...] promover condições para que diferentes pessoas representantes da sociedade civil ou da esfera estatal dos municípios construam e resgatem saberes significativos, metodologias e valores necessários numa prática dialógica para: i. fortalecimento da autonomia individual e coletiva necessárias à organização e ao progresso e controle social; ii. compreensão da diversidade e complexidade das questões ambientais, suas causas, seus efeitos e suas inter-relações; iii. o desenvolvimento de ações mobilizadoras junto às comunidades que contribuam para o encaminhamento de questões ambientais.

Além do município de Rio das Ostras o projeto trabalha com outros 12 municípios, sendo estes: Araruama, Arraial do Cabo, Saquarema, Cabo Frio, Armação dos Búzios, Casimiro de Abreu, Macaé, Carapebus, Quissamã, São Francisco de Itabapoana, Campos dos Goytacazes e São João da Barra. Tendo como primeiros estudos, para posterior diagnóstico, as seguintes etapas: 1) Visitas a ecossistemas e unidades de conservação (UC); 2) Visitas a escolas; 3) Visitas a organizações da sociedade civil (OSCs); 4) Levantamento de Políticas Públicas e Instrumentos da Gestão; 5) Levantamento dos impactos da Petrobras percebidos por grupos sociais. Assim foram desenvolvidos e pensados processos para a formação de cursos para educadores ambientais e de princípios em gestão ambiental voltados para professores e técnicos, representantes das secretarias de Meio 
Ambiente e de Educação e também lideranças locais da sociedade organizada de municípios da região dos lagos e norte-fluminense participantes do projeto, e a implantação de pólos de Educação Ambiental nos municípios.

Em Rio das Ostras, o pólo do projeto esta localizado no Parque dos Pássaros e tem contribuição do Núcleo de Educação Ambiental de Rio das Ostras que foi inaugurado em 2005. Além do trabalho do núcleo de EA e do projeto pólen, a secretaria de Meio Ambiente, Agricultura e Pesca no ano de 2007 se unificou aos já citados, fisicamente na sede do Parque, também para desenvolverem atividades de EA voltadas para os impactos da produção do petróleo.

Como exemplo do que vem sendo desenvolvido no município de Rio das Ostras, em trabalho de campo realizado em junho de 2011, foi possível participar do III Fórum do Projeto Pólen - Gestão Participativa do Petróleo, cujo tema foi Participação e Controle Social, que aconteceu no dia 04/06/11. A palestra foi ministrada pelo Prof. José Quintas, na Secretaria de Educação do próprio município. Estiveram presentes representantes do Núcleo de EA, da Petrobras e também da comunidade composto por um grupo de jovens que já estão imbuídos neste projeto e estão recebendo qualificação para atuarem como cidadãos ativos não só no processo de licenciamento como também em todo processo de EA da cidade. Desta forma, durante a palestra, dentre muitos temas citados, foram abordadas diferentes concepções de participação (políticas públicas, participação de grupos das sociedades, orçamento participativo, criação de conselho, etc.) e sobre democracia (cidadania, igualdade de oportunidades, pluralidade, diversidade etc.). Na tentativa de trazer os diferentes grupos envolvidos à discussão participativa, a percepção de meio ambiente de forma coletiva foi a tônica da palestra, para que assim houvesse uma aproximação do debate nos diferentes âmbitos de formação e pratica social para a EA. Assim Quintas (1995), afirma:

\begin{abstract}
o esforço da Educação Ambiental deveria ser direcionado para a compreensão e busca da superação das causas estruturais dos problemas ambientais por meio da ação coletiva e organizada. [...] a leitura da problemática ambiental se realiza sob a ótica da complexidade do meio social e o processo educativo deve pautar-se por uma postura dialógica, problematizadora e comprometida com transformações estruturais da sociedade, de cunho emancipatório. Aqui acredita-se que, ao participar do processo coletivo de transformação da sociedade, a pessoa, também, estará se transformando (QUINTAS, 1995, s.n.).
\end{abstract}

O grupo atua não somente dentro do projeto com o licenciamento ambiental, mas também com a conscientização da população na preservação do meio ambiente. São programados eventos, principalmente em conjunto com as escolas municipais e a secretaria de meio ambiente, onde os voluntários visitam os bairros levando informações, além de projetos que focam em ações que visam à limpeza das praias, lagoas e seu entorno, sendo estes os principais destinos turísticos da região. A ideia destas atividades é fazer com que a comunidade local perceba a importância da preservação do meio ambiente, para que posteriormente consiga passar aos visitantes e turistas os princípios básicos da EA, além de ser uma forma de conservação do produto turístico do município. 


\section{Parque dos Pássaros - Rio das Ostras (RJ)}

O Parque dos Pássaros hoje é considerado como referência em EA no município de Rio das Ostras por abrigar a sede do Núcleo de Educação Ambiental. Localiza-se na Rua Petrópolis, s/n, no bairro Jardim Mariléa, em Rio das Ostras (Figura 2). Possui 8,13 hectares de superfície e $1,36 \mathrm{~km}$ de perímetro. Abrange $0,035 \%$ do total do município de Rio das Ostras e possui visitação, estudos e pesquisas como atividades de uso público (PMRO, 2005).

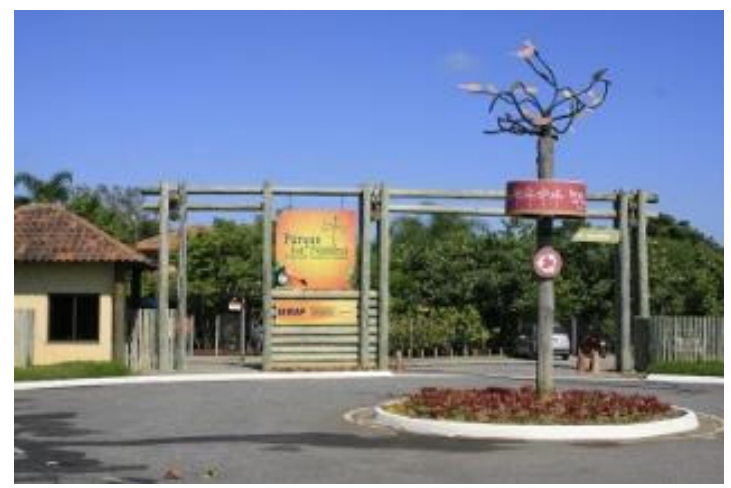

Figura 2: Entrada do Parque dos Pássaros. Foto: Bruna Cirino Carvalho, 2011.

Figure 2: Entering of the Parque dos Pássaros (Bird Park). Photo: Bruna Cirino Carvalho, 2011.

A área do parque faz parte da região do Jardim Mariléia e Mariléia Chácaras, que anteriormente fazia parte de uma antiga fazenda que foi dividida em lotes de terreno e chácaras.

Inicialmente esta ocupação ocorreu de forma desordenada e com ações danificadoras ao ambiente. Com a II Conferência Municipal de Meio Ambiente, realizada em 2000, foi reivindicada a proteção desta área verde através da criação de uma Unidade de Conservação (UC) (PMRO, 2005).

O projeto de Plano de Manejo do Parque foi elaborado no período de outubro de 2003 a novembro de 2004, resultante do seu decreto municipal de criação $n^{\circ}$ 091/2002, em 29 de novembro de 2002. A Zona de Amortecimento desta UC é constituída, em sua maioria, por propriedades privadas, com pequeno comércio local, instituições religiosas e algumas indústrias consideradas de baixo potencial poluidor, algumas creches, escolas de nível fundamental, ginásio poliesportivo, órgãos públicos municipais, estação de tratamento de esgoto, entre outros itens urbanos (OLIVEIRA; PRIOSTE; SOUZA, 1999)

(...) o parque dos pássaros, tendo como objetivo central a preservação ambiental e o desenvolvimento de práticas tecnicamente, socialmente e ambientalmente sustentáveis, agregará riqueza e status ao município onde estará sediado e aos municípios vizinhos, pela criação de novas possibilidades de trabalho, lazer e de uma nova forma de ocupação que respeita e acrescenta muito ao ecossistema silvestre da região (PLANO DE MANEJO, p. 16) 
Este projeto de grande significado social e ecológico só foi idealizado a partir do medo de que Rio das Ostras fosse depredado pela urbanização desenfreada, em conjunto com um Turismo mal administrado. Ele tem, portanto, premissas de proteção e recuperação ambiental equiparadas ao bem estar e conforto humanos, aproximando o homem da natureza (JARDIM; PINTO, 2008).

O Parque dos Pássaros é uma Unidade de Conservação de Proteção Integral. Sendo permitida somente a manutenção dos ecossistemas livres de alterações causadas por interferência humana, admitido apenas o uso indireto dos seus atributos naturais - que não envolva consumo, coleta, dano ou destruição dos recursos naturais (SNUC, 2000).

Inaugurado em 20 de Dezembro de 2004 e mantido pela Secretaria de Meio Ambiente, Agricultura e Pesca, com intuito de preservar as áreas de brejo e matas ciliares, tem a missão de, além de incentivar a visitação e o desenvolvimento de atividades dentro do Parque, avenha a promover a EA aos moradores e turistas, e que estees tenham mais uma opção de lazer, já que a cidade é conhecida pela massificação do turismo de sol e mar.

(...) projeto onde a preservação ambiental está sendo aliada ao desenvolvimento sustentável tanto social quanto do meio ambiente, trazendo mais uma opção de lazer ecológico ao riostrense e ao turista em geral. O trabalho que o Programa de Educação e Comunicação Ambiental do Projeto Parque dos Pássaros vem desenvolvendo junto às escolas do município e as comunidades, em especial a do bairro Jardim Mariléa, vai proporcionar uma análise e avaliação da visão da população de Rio das Ostras sobre esta Unidade de Conservação (PLANO DE MANEJO, p. 89). vos:

O parque como unidade de conservação ambiental, atende aos seguintes objeti-

+ Preservar as áreas com matas ciliares e as áreas de brejos e alagados que são sítios de abrigo e reprodução de espécies migratórias e ameaçadas de extinção;

+ Preservar e conservar os remanescentes florestais e de vegetação especifica da restinga;

+ Assegurar a continuidade de corredores biológicos da Mata Atlântica no Estado do Rio de Janeiro;

+ Garantir a diversidade e o endemismo de flora e fauna pela ampliação de nichos ecológicos;

+ Propiciar campo permanente para a pesquisa científica orientada ao reconhecimento e sobrevivência da biodiversidade e dos demais elementos;

+ Oferecer bases para a educação e interpretação ambiental e a recreação em contato com a natureza; 
O parque conta com duas trilhas, que recebem visitas guiadas, estas são cimentadas e planas com percursos somados superiores a um quilômetro (Figuras $3 \mathrm{e}$ 4). Uma das trilhas esta distribuída pela mata com variação de fauna e flora e também com uma porção arenosa de restinga. A outra trilha esta direcionada ao viveiro de pássaros de onde se pode observar as espécies com informações, em placas explicativas, sobre a vida destas espécies. As atividades desenvolvidas são de interpretação, com pontos de observação e descanso.
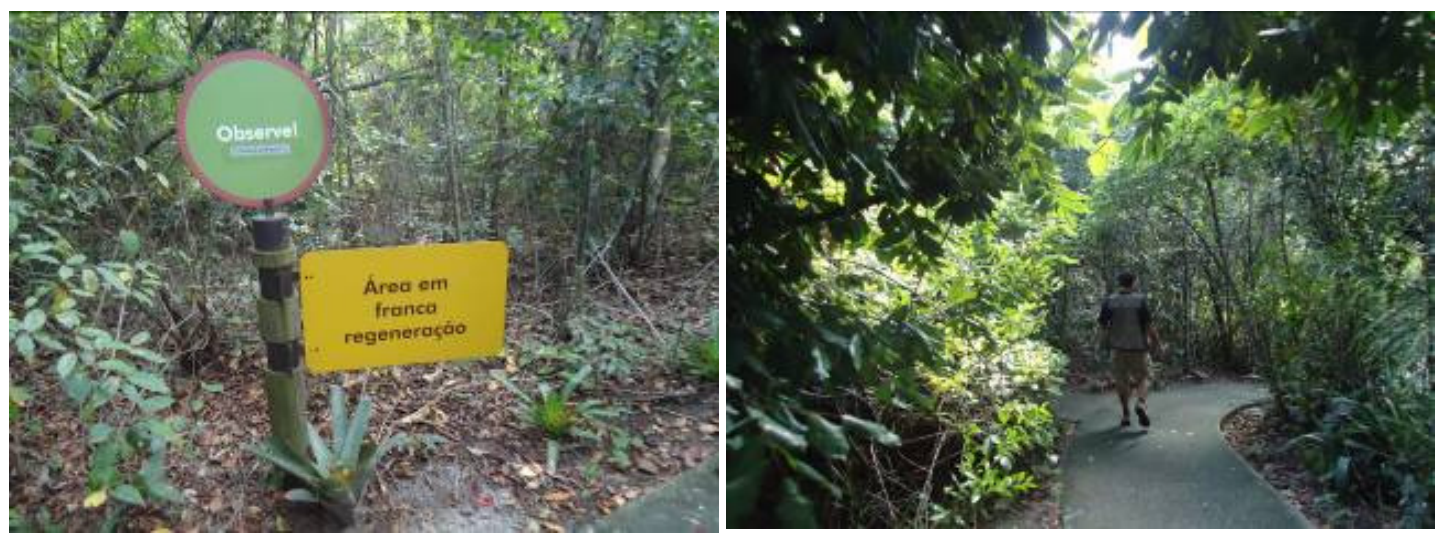

Figuras 3 e 4: Parte das trilhas com placas interpretativas e percurso cimentado. Foto: Bruna Cirino Carvalho, 2011.

Figures 3 and 4: Part of the trails with interpretive signs and cemented pathway.

Photo: Bruna Cirino Carvalho, 2011.

O parque conta ainda com: um centro de visitantes, um viveiro de pássaros, uma biblioteca e videoteca, o centro de estudos da flora / herbário, o centro de estudos da fauna e o núcleo de educação ambiental.

O centro de visitantes, logo na entrada, serve para atende e orientar os visitantes, conta ainda com um espaço de exposições (Figuras 5 e 6 ).

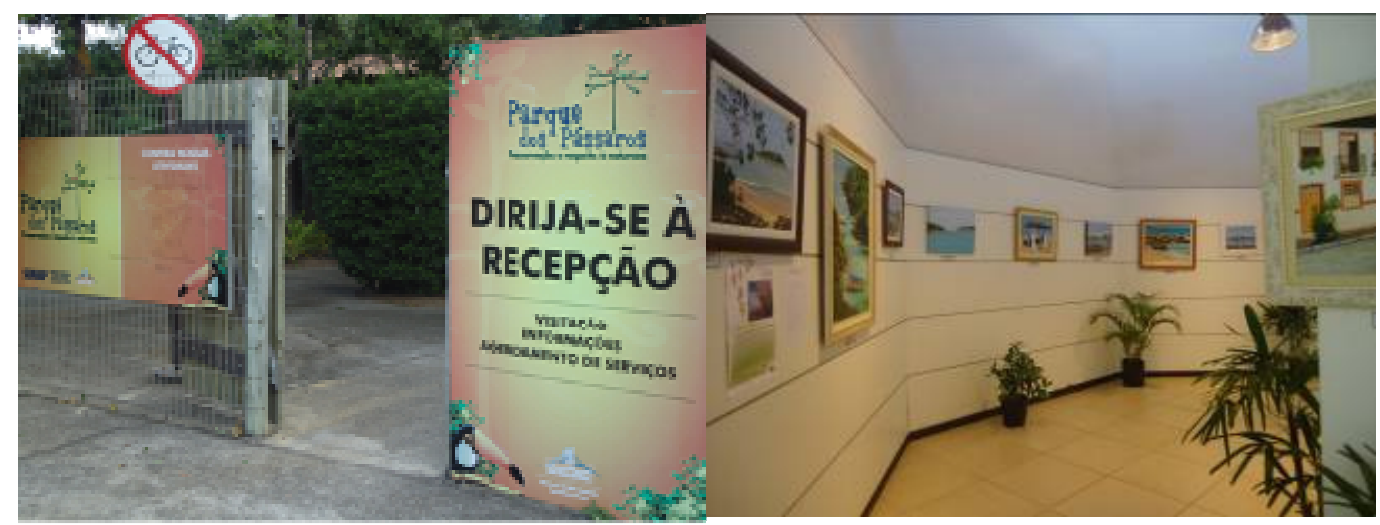

Figuras 5 e 6: Entrada da Recepção e espaço de exposição. Foto: Bruna Cirino Carvalho, 2011.

Figures 5 and 6: - Entering of the reception and exhibition space. Photo: Bruna Cirino Carvalho, 2011. 
O viveiro dos pássaros abriga elementos da avifauna brasileira (Figuras 7 e 8).

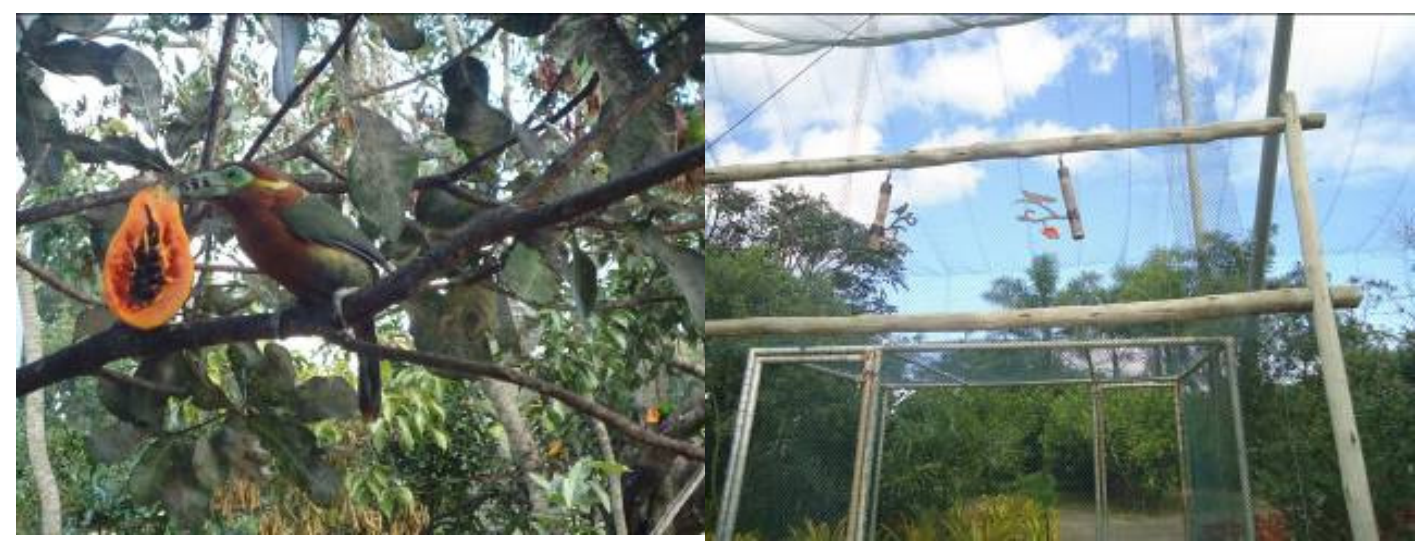

Figuras 7 e 8: Viveiro dos pássaros. Foto: Bruna Cirino Carvalho, 2011.

Figures 7 and 8: Nursery birds. Photo: Bruna Cirino Carvalho, 2011.

1. A biblioteca/videoteca foi planejada para atender grupos escolares e pessoas com interesses sobre o bioma Mata Atlântica.

2. O centro estudos da flora disponibiliza dados e técnicas de conservação, recuperação e preservação ambiental.

3. O centro de estudos da fauna disponibiliza informações a quem deseja se aprofundar no conhecimento dos animais existentes na área do parque.

O núcleo de educação ambiental atua no desenvolvimento de programas e atividades educativas, no aperfeiçoamento de técnicos, alunos e professores, e na capacitação de monitores, guias mirins e educadores ambientais, por meio de oficinas preparatórias e de reciclagem. Atua ainda como núcleo de geração de materiais educativos, didáticos e técnicos, para divulgar o parque e ressaltar a importância da conservação desta representação de mata Atlântica.

Durante os dias úteis, quando o parque recebe a visita de alunos das escolas locais, são desenvolvidas atividades lúdicas e de noções de EA. Estes podem conhecer as trilhas ecológicas, que contam com plantas variadas (medicinais, ornamentais, frutíferas), e receber informações sobre conservação e replantio de espécies nativas.

O Parque dos Pássaros torna-se referencia de ecoturismo e práticas de EA no município, tendo como principal objetivo a inserção da população local nos programas desenvolvidos. Para Ruschmann (1997) a educação para o turismo ambiental deverá ser desenvolvida por meio de programas informais, inserindo o "cidadão-turista" a participar de forma consciente visando proteção do meio ambiente. Sendo isso não somente durante as férias, mas também no cotidiano e no local de residência permanente. 
Assim a EA tem por objetivo o desenvolvimento sustentável, incluindo práticas de turismo sustentável, a melhoria da qualidade de vida (da população local e dos visitantes) e a contribuição do sentimento de pertencimento dos sujeitos com a natureza, para que assim possam se ver como parte integrante destes espaços passando a preservá-los.

Para tal, as atividades desenvolvidas visam oferecer aos visitantes experiências com a fauna e a flora locais, além de indicar formas de manter a qualidade do meio ambiente. Para que ocorra a sustentabilidade, é necessário que todos se envolvam nos programas de preservação e educação ambiental tomando consciência da importância do local não só para o turismo e atividades de lazer, mas para manter o equilíbrio natural. Para contribuir a reflexão da EA para a atividade turística Xavier (2002) afirma:

O conhecimento do problema consiste em tratar a Educação Ambiental, não para o turismo, mas sim, pelo turismo. Assim, pode ser apontada como alternativa, talvez para a solução de diversos problemas, sobretudo na busca de melhoria da qualidade de vida do homem que incorpora a dimensão do turismo. Referimo-nos a tudo isso, por acreditar na importância da educação para o meio ambiente em áreas turísticas, pois, turismo e meio ambiente constituem um todo, indivisível (XAVIER, 2002, p. 82).

\section{Conclusão}

No contexto ecoturístico, nota-se a humanização dos espaços, com o desenvolvimento de atividades que primem pela percepção ambiental, desta forma a escoIha das atividades a serem realizadas, além das técnicas e procedimentos que devem ser voltados aos parâmetros da EA. A EA atua na construção de uma conscientização ambiental, para que assim os sujeitos consigam se "ver" enquanto componente do meio ambiente e não como dominadora da natureza.

Deve-se levar em consideração, a dinâmica ecossistêmica, que muitas vezes independem das ações humanas, apesar de sua interação. Assim a importância da experiência de estar na natureza, pode ser um importante laboratório de auto questionamento. Destaca-se a necessidade e importância de cuidar do lugar para as gerações futuras. A interação entre o homem e o meio ambiente, não pode ser conflituosa, sendo assim a possibilidade e aumento das visitações pode ser possível, mas estando ciente da preservação para as gerações futuras.

No caso do município de Rio das Ostras com o Parque dos Pássaros, o ambiente foi preparado para receber a visitação de forma guiada e explicativa. A intenção inicial foi a criação de mais um ponto turístico para a cidade que se destaca como ponto de turismo de "sol e mar", tratando de transformar o turismo como uma atividade para o ano todo e não só sazonal.

A ampliação do trabalho do Núcleo de Educação Ambiental, principalmente com a instalação de suas dependências no parque, tornou o espaço uma referencia das atividades Ecoturísticas e desenvolvedora da EA informal. Trazendo não só alu- 
nos de escolas regulares, mas na tentativa de divulgar os trabalhos para toda a comunidade local assim como para os turistas que visitam a cidade.

Assim o processo educativo ambiental tem de ser composto por contato, reflexão e ação. Onde no primeiro momento o contato com a natureza gera reflexões e percepções, e por fim o sujeito se sensibiliza com as questões ambientais e se conscientiza de seus atos, assumindo um papel de responsabilidade social e ambiental.

Portanto o ecoturismo não pode ser visto e/ou desenvolvido unicamente como um segmento turístico, mas sim como uma atividade que se compromete com as questões ambientais, com programas de curta, media e longa duração que ainda não vem ocorrendo com o apoio aos projetos de EA fomentados pela Petrobras em Rio das Ostras. No caso do Parque dos Pássaros, observa-se que o Projeto Pólen vem se restringindo apenas ao segmento educacional, separado do segmento turístico. Os projetos vem abarcando apenas a comunidade escolar e a sociedade organizada (seus moradores), sem se preocupar em como haverá o incentivo da transmissão desse conhecimento (EA) para os visitantes/turistas (que se restringem apenas em continuar com o turismo "sol e mar"), não mostrando a importância de se conservar/ preservar o ambiente (turismo na natureza). A promoção e incentivo de atitudes de conservação e conscientização do comportamento social mediante a natureza devem ser priorizados e a EA é um dos segmentos que não podem faltar neste processo.

\section{Referências bibliográficas}

BECKER, B. Políticas e planejamento do turismo no Brasil. In: YÁZIGI, E.; CARLOS, A. F. A.; CRUZ, R. C. A. (org.). Turismo: Espaço, Paisagem e Cultura. São Paulo: Hucitec, 1996.

BEZERRA, T. M. O.; FELICIANO, A. L. P.; ALVES, A. G. C. Percepção ambiental de alunos e professores do entorno da estação ecológica de caetés - região metropolitana do Recife -PE. Revista Biotemas, v. 21, n.1, p. 147-160, 2008.

COSTA, V. C. da; COSTA, N. M. C. da. Educação Ambiental pelo Ecoturismo, em Unidades de conservação: uma proposta efetiva para o Parque Estadual da Pedra Branca (PEPB)-RJ. In: PEDRINI, A. G. (Org.) Repensando o Ecoturismo a luz da Educação, 2005.

COSTA, N. M. C. Ecoturismo: Abordagens e Perspectivas Geográficas. In.: COSTA, N. M. C.; NEIMAN, Z.; COSTA, V. C. (orgs.) Pelas trilhas do ecoturismo. São Carlos: RiMa, 2008.

CRUZ, R.C.A. Introdução à geografia do turismo. São Paulo: Roca, 2003. 2ª Ed. CRUZ, R.C.A. Geografia do Turismo de Lugares a Pseudo-Lugares. São Paulo: Roca, 2007.

JARDIM, M. E.; PINTO, S. Interpretação da trilha ecológica do Parque Natural Municipal dos Pássaros. Rio de Janeiro: Prefeitura Municipal de Rio das Ostras, 2008.

OLIVEIRA, A. C.; PRIOSTE, M. A. O; SOUZA, T. C. Boletim do Observatório Ambiental Alberto Ribeiro Lamego, Campos dos Goytacazes/RJ, v. 3 n. 1, p. 135-148, jan. / jun. 2009. 
Carvalho, B.C.; Costa, V.C.

OLIVEIRA, L.; MACHADO, L. M. C. P. Percepção, Cognição, Dimensão Ambiental e Desenvolvimento com Sustentabilidade. In: Reflexões sobre a geografia física no Brasil. VITTE, A. C.; GUERRA, A. J. T. (orgs.). Rio de Janeiro: Bertrand Brasil, 2004.

ORGANIZACAO MUNDIAL DE TURISMO-OMT. Guia de desenvolvimento do turismo sustentável. Porto Alegre: Bookman, 2003.

PLANO DE MANEJO DO PARQUE DOS PÁSSAROS. Projeto de Consolidação do Parque dos Pássaros. Rio de Janeiro: Prefeitura Municipal de Rio das Ostras, 2004.

QUINTAS, J. Introdução à Gestão Ambiental Pública. Revista Brasília: Ibama , 2ª ed. 2006.

QUINTAS, J.; GUALDA, M. J. A Formação do Educador para Atuar no Processo de Gestão Ambiental. Brasília: Ed. IBAMA, 1995.

REIGOTA, M. Meio ambiente e representação social. $7^{\circ}$ ed. São Paulo: Cortez: 1997.

RODRIGUES, A. M. A produção e o consumo do espaço para o turismo e a problemática ambiental. In. : YÁZIGI, E.; CARLOS, A. F. A.; CRUZ, R. C. A. (org.) Turismo: espaço, paisagem e cultura. $2^{\circ}$ edição. São Paulo: Hucitec, 1999.

RUSCHMANN, D. Turismo e planejamento sustentável: A Proteção do Meio Ambiente. 3ed. São Paulo: Papirus, 1997.

RUSCHMANN, D. O planejamento do turismo e a proteção do meio ambiente. São Paulo: ECA/USP, 1994.

SANTOS, M. Por uma outra globalização: Do pensamento único à consciência universal. Rio de Janeiro: Record, 2003.

SANTOS, M. A redescoberta da Natureza. São Paulo: FFLCH/USP, 1992. (aula inaugural da FFLCH/USP, proferida em 13/3/1992). Disponível em www.usp.br

SORRENTINO, M.; TRAJBER, R.; RAYMUNDO, M. H. A.; Biodiversidade e Educação Ambiental. In.: NEIMAN, Z.; JUNQUEIRA, V. (org). Educação Ambiental e Conservação da Biodiversidade. São Paulo: Ed. Manole, 2007.

SNUC - Sistema Nacional de Unidades de Conservação; Lei 9.985 de 18 de julho de 2000; Ministério do Meio Ambiente. <disponível em: http://www.planalto.gov.br/ ccivil 03/leis/L9985.htm>

XAVIER, H. Educação Ambiental: caminho para a sustentabilidade ecológica no turismo. In:. BARRETO, M.;TAMANINI, E. (Orgs.). Redescobrindo a Ecologia no Turismo. Caxias do Sul: EDUCS, 2002.

WEARING, S.; NEIL, J. Ecoturismo: Impactos, potencialidades e possibilidades. São Paulo: Manole, 2001. 
Bruna Cirino Carvalho: Universidade do Estado do Rio de Janeiro, Rio de Janeiro, RJ, Brasil.

Email: brunacirino@gmail.com

Link para o currículo Lattes: http://lattes.cnpq.br/6402574720152630

Vivian Castilho da Costa: Universidade do Estado do Rio de Janeiro, Rio de Janeiro, RJ, Brasil.

Email: vivianuerj@gmail.com

Link para o currículo: http://lattes.cnpq.br/3181407490194397

Data de submissão: 01 de julho de 2012

Data de recebimento de correções: 20 de novembro de 2012

Data do aceite: 20 de novembro de 2012

Avaliado anonimamente 